\title{
Path independence of climate and carbon cycle response over a broad range of cumulative carbon emissions
}

\author{
T. Herrington and K. Zickfeld \\ Department of Geography, Simon Fraser University, Burnaby, Canada \\ Correspondence to: K. Zickfeld (kzickfel@sfu.ca)
}

Received: 23 May 2014 - Published in Earth Syst. Dynam. Discuss.: 17 June 2014

Revised: 2 October 2014 - Accepted: 13 October 2014 - Published: 24 November 2014

\begin{abstract}
Recent studies have identified an approximately proportional relationship between global warming and cumulative carbon emissions, yet the robustness of this relationship has not been tested over a broad range of cumulative emissions and emission rates. This study explores the path dependence of the climate and carbon cycle response using an Earth system model of intermediate complexity forced with 24 idealized emissions scenarios across five cumulative emission groups $(1275-5275 \mathrm{Gt} C)$ with varying rates of emission. We find the century-scale climate and carbon cycle response after cessation of emissions to be approximately independent of emission pathway for all cumulative emission levels considered. The ratio of global mean temperature change to cumulative emissions - referred to as the transient climate response to cumulative carbon emissions (TCRE) is found to be constant for cumulative emissions lower than $\sim 1500 \mathrm{Gt} C$ but to decline with higher cumulative emissions. The TCRE is also found to decrease with increasing emission rate. The response of Arctic sea ice is found to be approximately proportional to cumulative emissions, while the response of the Atlantic Meridional Overturning Circulation does not scale linearly with cumulative emissions, as its peak response is strongly dependent on emission rate. Ocean carbon uptake weakens with increasing cumulative emissions, while land carbon uptake displays non-monotonic behavior, increasing up to a cumulative emission threshold of $\sim 2000 \mathrm{GtC}$ and then declining.
\end{abstract}

\section{Introduction}

Recent studies with coupled climate-carbon cycle models have shown that global mean temperature change is independent of emission pathway and approximately proportional to cumulative $\mathrm{CO}_{2}$ emissions (Allen et al., 2009; Matthews et al., 2009; Zickfeld et al., 2009, 2012; Gillett et al., 2013). Results have also suggested that global mean temperature remains approximately constant for centuries to millennia after $\mathrm{CO}_{2}$ emissions cease (Plattner et al., 2008; Eby et al., 2009; Solomon et al., 2009; Frölicher and Joos 2010; Gillett et al., 2011; Zickfeld et al., 2013).

These studies can be characterized as using the "cumulative emissions framework", which relates the instantaneous or century-scale response of global mean temperature to the cumulative $\mathrm{CO}_{2}$ emissions over a certain period of time. The ratio of global mean temperature change to cumulative $\mathrm{CO}_{2}$ emissions, referred to as the transient climate response to cu- mulative carbon emissions (TCRE), is a measure of both the carbon cycle response to $\mathrm{CO}_{2}$ emissions and the physical climate response to atmospheric $\mathrm{CO}_{2}$ increase, and has been suggested as a useful benchmark for model intercomparison (Matthews et al., 2009; Gillett et al., 2013). The cumulative emissions framework is also useful to climate policy discussions for it enables researchers to express temperature targets, such as the $2{ }^{\circ} \mathrm{C}$ target adopted by many countries and international organizations, in terms of a carbon emission "budget" (England et al., 2009; Meinshausen et al., 2009; Zickfeld et al., 2009; Messner et al., 2010).

Several studies have explored the robustness of the proportional relationship between the century-scale and instantaneous global mean temperature change and cumulative emissions. Studies with both Earth system models of intermediate complexity (EMICs) (Eby et al., 2009; Zickfeld et al., 2009) and complex Earth system models (ESMs) (Zickfeld et al., 2012; Nohara et al., 2013) have demonstrated 
that the century-scale temperature response after cessation of emissions is independent of emission pathway. Zickfeld et al. (2012), using the Canadian Earth System Model (CanESM), showed that the path independence holds also for a range of other climate variables (atmospheric $\mathrm{CO}_{2}$ concentration, precipitation, sea ice cover, Atlantic Meridional Overturning Circulation). Nohara et al. (2013) obtained similar results with the Community Earth System Model (CESM), except for the response of the Atlantic Meridional Overturning Circulation (AMOC), which was found to exhibit path dependence in a cumulative $\mathrm{CO}_{2}$ emission overshoot scenario.

A range of studies also explored the robustness of the proportional relationship between the instantaneous global mean temperature change and cumulative emissions by evaluating the constancy of the TCRE. Matthews et al. (2009), using results from Coupled Climate Carbon Cycle Model Intercomparison Project $\left(\mathrm{C}^{4} \mathrm{MIP}\right)$ simulations, found the TCRE to be constant up to cumulative emissions of about $2000 \mathrm{Gt}$ C. This result was confirmed by Gillett et al. (2013), who used results from the Coupled Model Intercomparison Project Phase 5 (CMIP5) $1 \% \mathrm{CO}_{2}$ increase experiment. Both studies tested the constancy of the TCRE for one emisson scenario only. Zickfeld et al. (2012) explored the TCRE for a set of scenarios with varying emission rates and found it to be approximately constant across scenarios. Krasting et al. (2014), on the other hand, using a range of scenarios with constant $\mathrm{CO}_{2}$ emission rates $\left(2-25 \mathrm{GtC} \mathrm{yr}^{-1}\right)$, found the TCRE to vary with emission rate. They found the TCRE to be highest at low and high emission rates, and lowest at present-day emission rates $\left(5-10 \mathrm{Gt} \mathrm{C} \mathrm{yr}^{-1}\right)$.

Previous studies exploring the proportional relationship between climate change and cumulative carbon emissions either focused on a single emission scenario (Matthews et al., 2009; Gillett et al., 2013) or on emission scenarios with cumulative $\mathrm{CO}_{2}$ emissions of up to about $2500 \mathrm{GtC}$ (Zickfeld et al., 2012; Nohara et al., 2013). Here we use the University of Victoria Earth System Climate Model (UVic ESCM) to explore the transient climate and carbon cycle response to emisson pathways spanning a broad range of cumulative $\mathrm{CO}_{2}$ emissions and $\mathrm{CO}_{2}$ emission rates. To this scope, we design a set of $\mathrm{CO}_{2}$ emission scenarios pertaining to five cumulative emission groups $(1275,2275,3275,4275$, and $5275 \mathrm{GtC}$ ). Each cumulative emission group includes a variety of peak-and-decline scenarios, an "overshoot" scenario (OVST) entailing negative $\mathrm{CO}_{2}$ emissions, and a "pulse" scenario (PULSE) with instantaneous $\mathrm{CO}_{2}$ release.

The paper begins with an overview of the UVic ESCM, followed by a description of the emission scenarios designed for the purpose of this study. Section 3 is divided into three main components. First, the transient response of the physical climate system is explored. Next, an analysis of the relationship between physical climate variables and cumulative emissions is presented, followed by an exploration of the car- bon cycle response. Finally, the paper ends with a summary of key findings and conclusions.

\section{Methods}

\subsection{Model description}

The study utilized the UVic ESCM version 2.9, which includes an ocean general circulation model coupled to a sea ice model, an energy-moisture balance model of the atmosphere, and land and ocean carbon cycle models. The ocean model consists of a primitive 3-D, 19-layer ocean general circulation model with isopycnal mixing and a Gent and McWilliams (1990) parameterization of the effect of eddyinduced tracer transport. Diapycnal mixing is modeled using a horizontally constant profile of diffusivity with values on the order of $0.3 \times 10^{-4} \mathrm{~m}^{2} \mathrm{~s}^{-1}$ in the pycnocline (Weaver et al., 2001; Eby et al., 2009). Coupled to the ocean model are a dynamic-thermodynamic sea ice model and a thermodynamic energy-moisture balance model of the atmosphere with dynamical feedbacks (Weaver et al., 2001). Land surface and terrestrial vegetation dynamics are modeled using a simplified version of the Hadley Centre Met Office Surface Exchange Scheme (MOSES) coupled to the Top-Down Representation of Interactive Foliage and Flora Including Dynamic vegetation model (TRIFFID) (Meissner et al., 2003). Ocean carbon is represented via an Ocean Carbon Cycle Model Intercomparison Project (OCMIP) type inorganic ocean carbon cycle model and a nutrient-phytoplankton-zooplankton-detritus marine ecosystem model (Schmittner et al., 2005). Sediment processes are represented using an oxic-only model of sediment respiration (Archer, 1996). Model coverage is global with a zonal resolution of $3.6^{\circ}$ and meridional resolution of $1.8^{\circ}$ (Weaver et al., 2001).

\subsection{Model simulations}

\subsubsection{Historical simulation}

The historical simulation was started from the model's preindustrial (year-1800) control configuration (with a $\mathrm{CO}_{2}$ concentration of $284 \mathrm{ppm}$ ) and integrated to the year 2008 using the observed $\mathrm{CO}_{2}$ fossil fuel (Boden et al., 2012) emissions, along with radiative forcing from non- $\mathrm{CO}_{2}$ greenhouse gas (GHG) $\left(\mathrm{CH}_{4}, \mathrm{~N}_{2} \mathrm{O}\right.$, and halocarbons) and sulphate aerosols. The model was also forced with historical land-cover changes. Since $\mathrm{CO}_{2}$ emissions from landuse change (LUC) generated by the UVic ESCM are small, these emissions were complemented by externally prescribed LUC emissions to match the observations-based estimate of Houghton (2008). Natural forcings, including solar variations (due to changes in solar luminosity and orbital configuration) and volcanic eruptions, were applied using the observed forcing until 2000 and then kept at constant 2000 levels over the rest of the simulation. Between 1800 and 2008, 
Table 1. The 24 emission scenarios and their characteristics. Emissions include both fossil fuel and land-use change emissions. $\mathrm{Cu}$ mulative emissions are from year 1800 onward.

\begin{tabular}{|c|c|c|c|}
\hline $\begin{array}{l}\text { Cumulative } \\
\text { emissions }\end{array}$ & scenario & $\begin{array}{r}\text { Maximum } \\
\text { emission rate } \\
\left(\mathrm{GtC}_{\mathrm{yr}}^{-1}\right)\end{array}$ & $\begin{array}{r}\text { Year of } \\
\text { emission } \\
\text { cessation }\end{array}$ \\
\hline \multirow{4}{*}{$1275 \mathrm{GtC}$} & FAST & 14.1 & 2100 \\
\hline & VFAST & 17.4 & 2100 \\
\hline & OVST & 16.9 & 2100 \\
\hline & PULSE & 376.7 & 2010 \\
\hline \multirow[t]{5}{*}{$2275 \mathrm{GtC}$} & FAST & 17.1 & 2100 \\
\hline & MEDIUM & 14.9 & 2100 \\
\hline & SLOW & 11.5 & 2250 \\
\hline & OVST & 18.7 & 2100 \\
\hline & PULSE & 883.5 & 2010 \\
\hline \multirow[t]{5}{*}{$3275 \mathrm{GtC}$} & FAST & 19.1 & 2200 \\
\hline & MEDIUM & 14.7 & 2250 \\
\hline & SLOW & 12.9 & 2300 \\
\hline & OVST & 24.2 & 2250 \\
\hline & PULSE & 1390.4 & 2010 \\
\hline \multirow[t]{5}{*}{$4275 \mathrm{GtC}$} & FAST & 22 & 2250 \\
\hline & MEDIUM & 17 & 2300 \\
\hline & SLOW & 14.1 & 2350 \\
\hline & OVST & 28.2 & 2300 \\
\hline & PULSE & 1897.2 & 2010 \\
\hline \multirow[t]{5}{*}{$5275 \mathrm{GtC}$} & FAST & 24.9 & 2300 \\
\hline & MEDIUM & 21.1 & 2350 \\
\hline & SLOW & 15.9 & 2400 \\
\hline & OVST & 34.9 & 2350 \\
\hline & PULSE & 2404.1 & 2010 \\
\hline
\end{tabular}

the cumulative $\mathrm{CO}_{2}$ fossil fuel and LUC emissions were 347 and $227 \mathrm{Gt} \mathrm{C}$, respectively, resulting in a year- $2008 \mathrm{CO}_{2}$ concentration of $382 \mathrm{ppm}$.

\subsubsection{Future emission pathways}

Twenty-four idealized emission scenarios across five cumulative emission groups $(1275,2275,3275,4275$, and $5275 \mathrm{GtC}$ ) were designed (Table 1). These scenarios include both fossil fuel and land-use change emission, and span a variety of peak and decline scenarios with varying emission rates, as well as cumulative emission "overshoot" scenarios with negative emissions and instantaneous pulse scenarios (Fig. 1). The emission scenarios were designed by setting a target peak emission rate and a target year of emission cessation, and ensuring total cumulative emissions (from 1800 onwards) fit into one of the five aforementioned cumulative emission groups. The emission scenarios include a cumulative $1000-5000 \mathrm{GtC}$ of fossil fuel emissions as well as a cumulative $275 \mathrm{GtC}$ of externally prescribed LUC emissions. Prescribed LUC emissions follow the historical LUC emis- sions to 2008 and then decline linearly, reaching 0 by 2100 . In addition, the emission scenarios include $\sim 50 \mathrm{Gt} C$ of internally calculated LUC emissions from imposed land-use changes. Note that scenarios are labeled according to the total externally prescribed fossil fuel and LUC emissions (1275, $2275,3275,4275$, and $5275 \mathrm{Gt} \mathrm{C}$ )

Emission scenarios were used to force future simulations spanning the period 2008-3000. Simulations were run with the same forcings as over the historical period. Land use and solar, orbital, and volcanic radiative forcings were kept constant at year-2000 levels, while sulphate and non- $\mathrm{CO}_{2}$ GHGs followed the Special Report on Emission Scenarios (SRES) A2 scenario until 2010 and were held constant at year-2010 levels thereafter.

\section{Results and discussion}

\subsection{Physical climate changes}

\subsubsection{Atmospheric $\mathrm{CO}_{2}$ concentration}

Peak atmospheric $\mathrm{CO}_{2}$ concentration varies from $575 \mathrm{ppm}$ in the $1275 \mathrm{GtC}$ very fast scenario (VFAST) to $2521 \mathrm{ppm}$ in the $5275 \mathrm{GtC}$ PULSE scenario (Fig. 2). Scenarios with higher emission rates yield higher peak $\mathrm{CO}_{2}$ concentrations - a function of land and ocean carbon sinks being unable to keep up with faster emission rates (Eby et al., 2009; Zickfeld et al., 2012).

Though the short-term $\mathrm{CO}_{2}$ concentration varies by scenario, the $\mathrm{CO}_{2}$ concentration begins to converge after emission cessation for scenarios with the same cumulative emissions, and the long-term $\mathrm{CO}_{2}$ concentration (by the year 3000 ) is independent of the emissions rate - a characteristic which is common to all five cumulative emission groups.

Initially, the increased atmospheric $\mathrm{CO}_{2}$ concentration promotes increased photosynthesis and water use efficiency in plants (" $\mathrm{CO}_{2}$ fertilization"; Wullschleger et al., 2002), allowing for rapid uptake of $\mathrm{CO}_{2}$ by the land. However, as emissions cease and $\mathrm{CO}_{2}$ declines while surface air temperature remains elevated, the land becomes a weak net carbon source, leaving the much slower ocean sink to take up excess $\mathrm{CO}_{2}$ (Fig. 9).

\subsubsection{Surface air temperature}

The short-term response of global mean surface air temperature (SAT) is dependent on emission scenario, with scenarios entailing higher maximum emission rates yielding a faster initial increase in temperature (Fig. 3). After emissions cease, however, temperature curves within a cumulative emission group converge towards a common value, suggesting that the long-term (year-3000) global mean temperature response is pathway independent and only dependent on the overall cumulative emissions (Eby et al., 2009; Zickfeld et al., 2009, 2012). Remarkably, despite substantially higher peak $\mathrm{CO}_{2}$ concentrations in the OVST and PULSE scenarios, the peak 

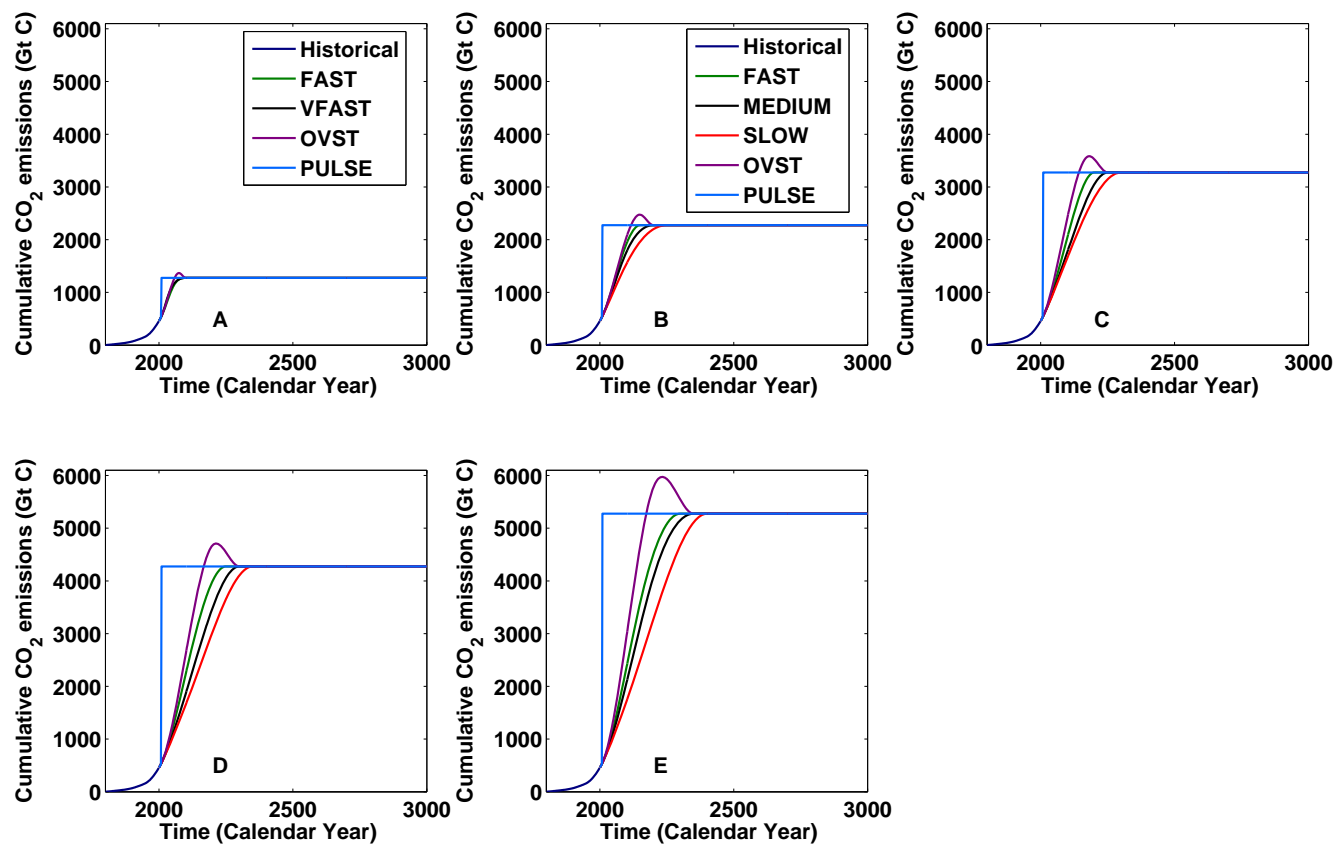

Figure 1. Global cumulative $\mathrm{CO}_{2}$ emissions (fossil fuel plus LUC emissions) for the $1275-5275 \mathrm{Gt} C$ cumulative emission scenarios. (a) $1275 \mathrm{Gt} \mathrm{C}$ scenarios, (b) $2275 \mathrm{Gt} \mathrm{C}$ scenarios, (c) $3275 \mathrm{Gt} \mathrm{C}$ scenarios, (d) $4275 \mathrm{Gt} \mathrm{C}$ scenarios, and (e) $5275 \mathrm{Gt} \mathrm{C} \mathrm{scenarios.} \mathrm{Note:} \mathrm{legend}$ for (b) also applies to (c-e).
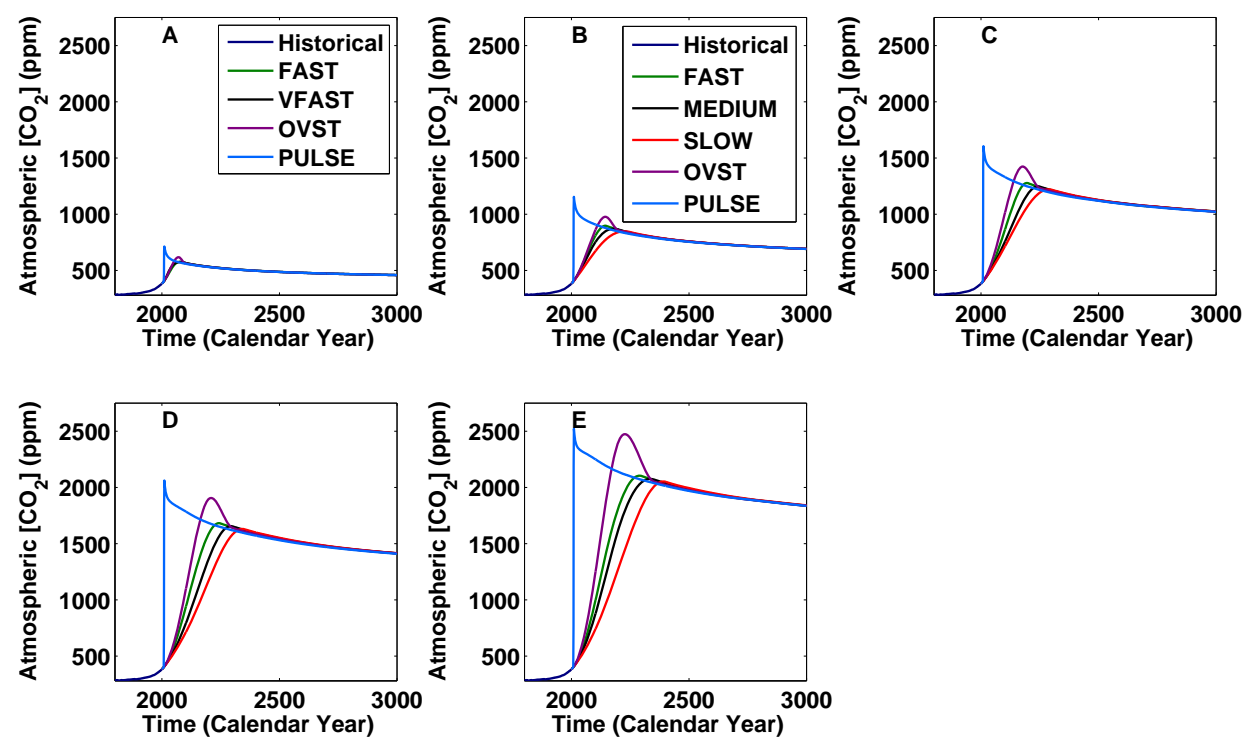

Figure 2. Atmospheric $\mathrm{CO}_{2}$ concentration for the $1275-5275 \mathrm{Gt} \mathrm{C}$ scenarios. (a) $1275 \mathrm{Gt} \mathrm{C}$ scenarios, (b) $2275 \mathrm{Gt} \mathrm{C}$ scenarios, (c) $3275 \mathrm{Gt} \mathrm{C}$ scenarios, (d) $4275 \mathrm{Gt}$ C scenarios, and (e) $5275 \mathrm{Gt} \mathrm{C}$ scenarios. Note: legend for (b) also applies to (c-e). 

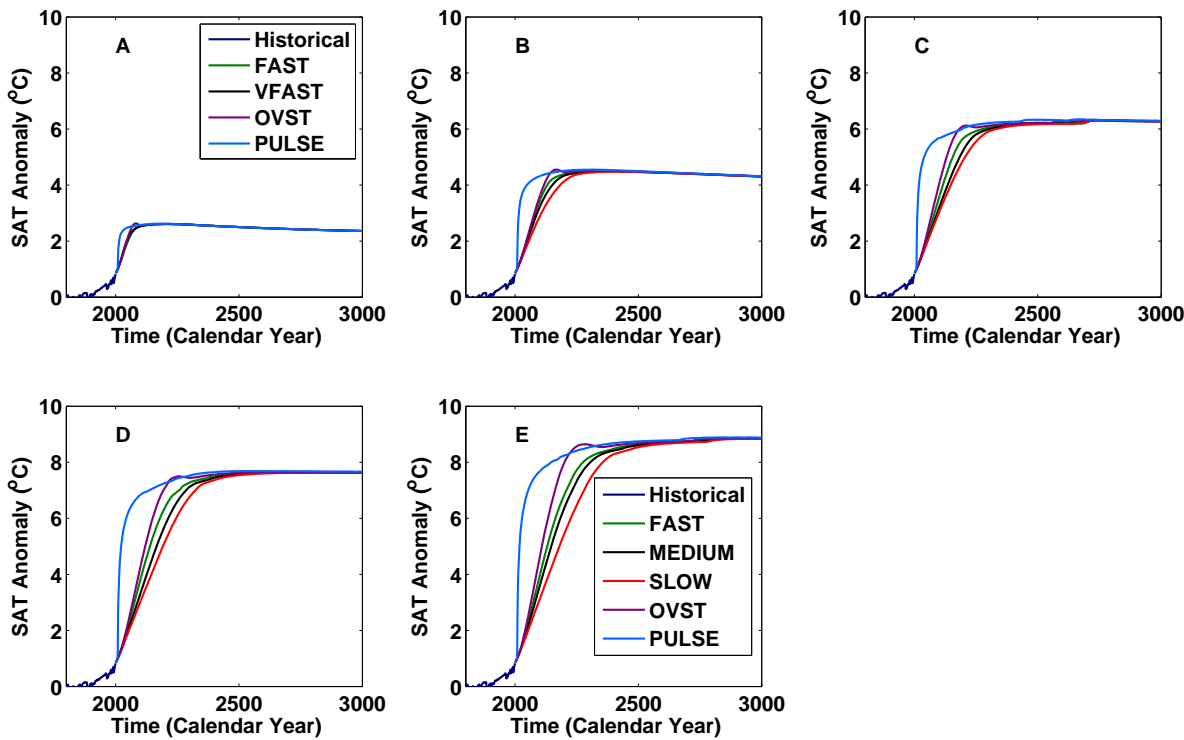

Figure 3. Global mean surface air temperature (SAT) anomaly relative to the year 1800 for the $1275-5275 \mathrm{Gt} \mathrm{C}$ scenarios. (a) $1275 \mathrm{Gt} \mathrm{C}$ scenarios, (b) $2275 \mathrm{Gt} \mathrm{C}$ scenarios, (c) $3275 \mathrm{Gt} \mathrm{C}$ scenarios, (d) $4275 \mathrm{Gt} \mathrm{C}$ scenarios, and (e) $5275 \mathrm{Gt} \mathrm{C}$ scenarios. Note: legend for (e) also applies to (b-d).
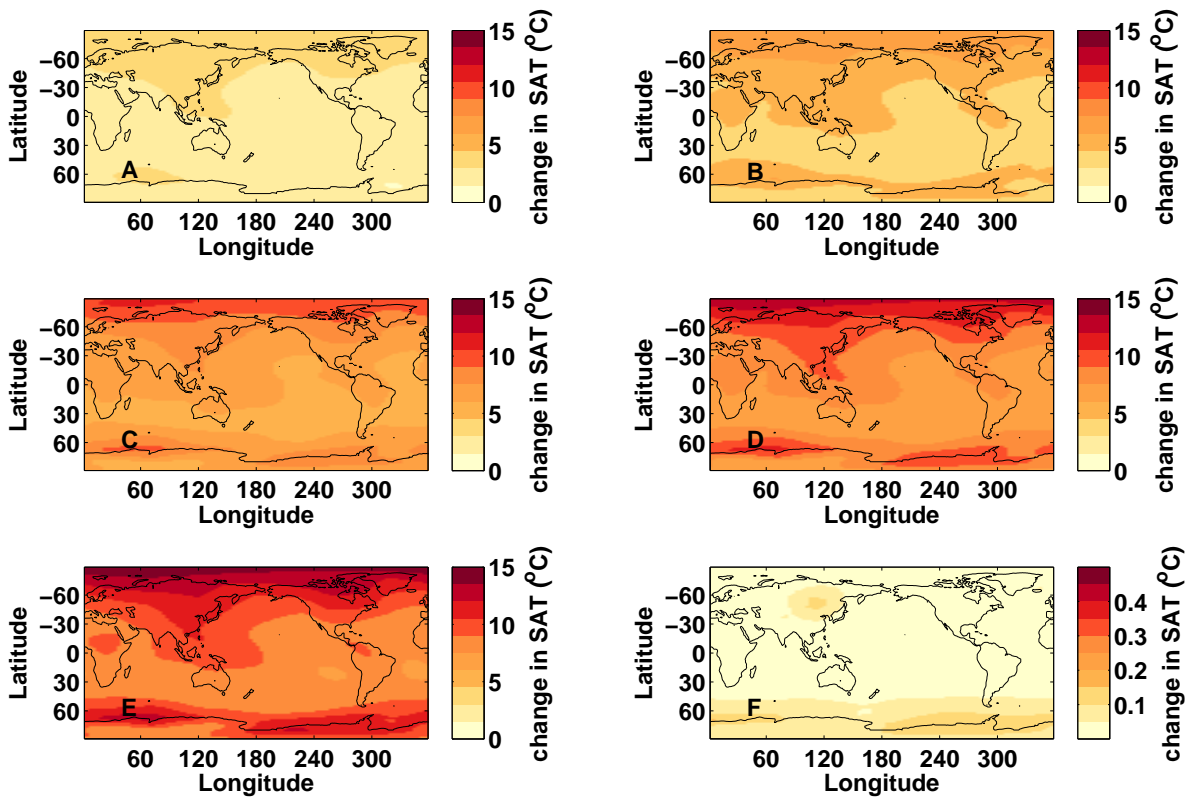

Figure 4. Year-3000 surface air temperature (SAT) anomalies relative to 1800 for select scenarios. (a) 1275 Gt C FAST, (b) 2275 Gt C FAST, (c) 3275 Gt C FAST, (d) 4275 Gt C FAST, (e) 5275 Gt C FAST, and (f) 5275 Gt C PULSE minus SLOW. Note that the color scale for (f) is different from that for the other panels.

temperature is nearly identical to that of the other scenarios in the same cumulative emission group, suggesting that the peak temperature anomaly is also approximately independent of the emission rate (Allen et al., 2009). The year-3000 global mean temperature anomaly (relative to the year 1800) ranges between $2.4^{\circ} \mathrm{C}$ for the $1275 \mathrm{GtC}$ scenarios and $8.9^{\circ} \mathrm{C}$ for the $5275 \mathrm{GtC}$ scenarios. The spatial pattern of tempera- ture change at the year 3000 is shown in Fig. 4 for one select scenario from each cumulative emission group.

The temperature anomaly after cessation of emissions is found to remain approximately constant, with lower cumulative emission groups (1275 and $2275 \mathrm{GtC}$ ) showing a slight temperature decline after peaking, and higher cumulative emission groups $(3275-5275 \mathrm{GtC})$ showing a slight 

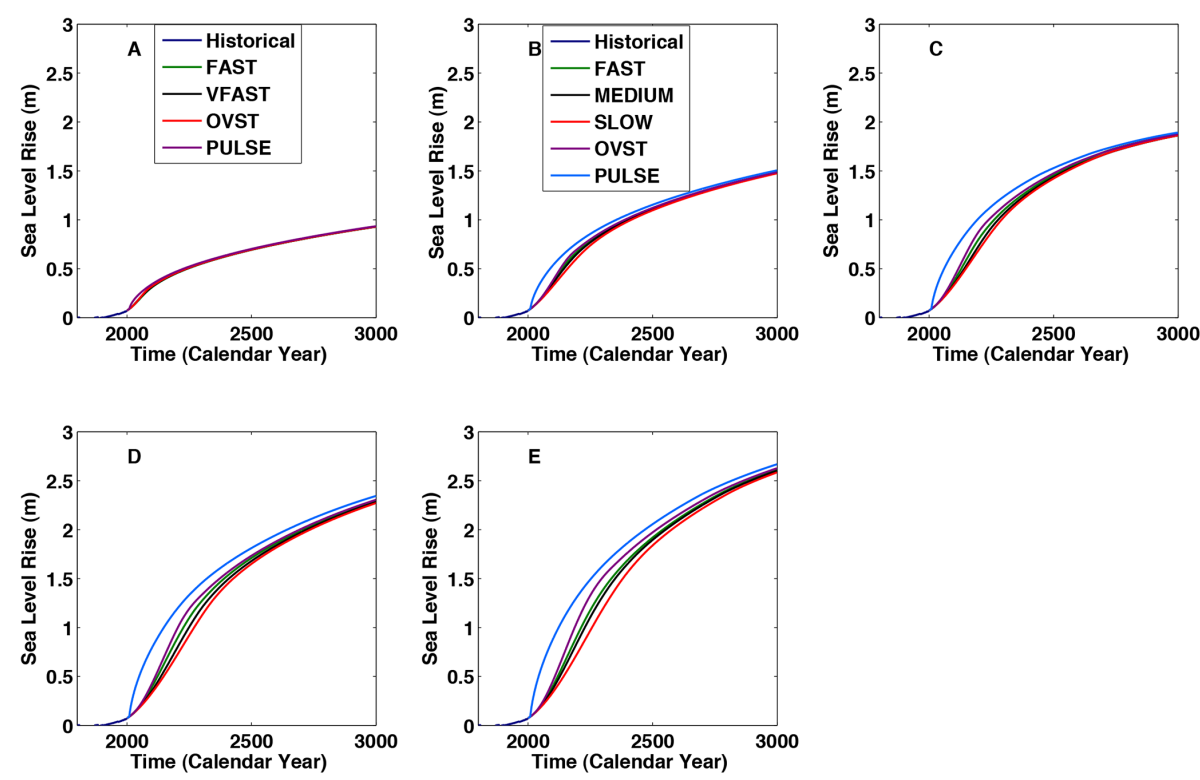

Figure 5. Global mean thermosteric sea level rise (relative to 1800) for the 1275-5275 Gt C scenarios. (a) $1275 \mathrm{Gt}$ C scenarios, (b) $2275 \mathrm{Gt} \mathrm{C}$ scenarios, (c) $3275 \mathrm{Gt} \mathrm{C} \mathrm{scenarios,} \mathrm{(d)} 4275 \mathrm{Gt} \mathrm{C}$ scenarios, and (e) $5275 \mathrm{Gt} \mathrm{C}$ scenarios. Note: legend for (b) also applies to (c-e).

temperature increase. The near constancy of global mean temperature after cessation of emissions is in agreement with earlier modeling studies (Matthews et al., 2008; Plattner et al., 2008; Eby et al., 2009; Solomon et al., 2009; Lowe et al., 2009; Frölicher and Joos, 2010; Gillett et al., 2011; Zickfeld et al., 2012) and is thought to arise because the cooling effect associated with declining $\mathrm{CO}_{2}$ is compensated by reduced ocean heat uptake (Eby et al., 2009).

A study by Frölicher et al. (2014) tested an instantaneous pulse scenario with cumulative carbon emissions of $1800 \mathrm{GtC}$ and found that surface air temperature increases for several centuries after an initial decrease following emission cessation. They suggest that this is due to the warming associated with a decrease in ocean heat uptake together with feedback effects arising in response to the geographic structure of ocean heat uptake overcompensating for the cooling associated with a decline in radiative forcing. In our simulations, surface air temperature decreases following emission cessation for cumulative emissions in the range $1275-2275 \mathrm{GtC}$ and increases for cumulative emissions of $4275-5275 \mathrm{Gt} C$. The reason for the slight continued increase in temperature following emission cessation in the larger cumulative emission groups in our study is that the climate system takes longer to equilibrate with the radiative forcing; i.e., the decline in ocean heat uptake is smaller, leading to larger warming.

We also found the regional temperature response at the year 3000 to be approximately independent of emission pathway. For instance, the maximum temperature difference between the $5275 \mathrm{Gt} C$ PULSE and SLOW scenarios at the year 3000 is $\sim 0.2^{\circ} \mathrm{C}$ over central Asia (Fig. $4 f$ ).

\subsubsection{Thermosteric sea level}

Global thermosteric sea level rise, defined as the rise in sea level due to thermal expansion of the ocean, is much slower to react to the increased radiative forcing than surface temperature. The year-3000 thermosteric sea level rise (relative to 1800 ) ranges from $0.9 \mathrm{~m}$ for the $1275 \mathrm{GtC}$ scenarios to $2.7 \mathrm{~m}$ for the $5275 \mathrm{GtC}$ PULSE scenario (Fig. 5). Though thermosteric sea level rise shows sensitivity to the emission rate for centuries after emissions cease (with faster emission rates yielding a faster initial sea level rise), the curves slowly converge over the course of the simulation, such that even in the $5275 \mathrm{GtC}$ simulations there is only a $0.08 \mathrm{~m}$ difference between the SLOW and PULSE simulations by the year 3000 .

The finding of path dependence of thermosteric sea level rise on century timescales is similar to the finding of Zickfeld et al. (2012) and Bouttes et al. (2013) and results from the proportionality of thermosteric sea level rise to the timeintegrated radiative forcing on those timescales (Bouttes et al., 2013). Convergence of the sea level response at the end of the 1200-year-long simulation for all cumulative emission groups, however, indicates that on longer timescales sea level rise is determined primarily by cumulative emissions.

\subsubsection{Arctic sea ice}

September Arctic sea ice disappears completely in the $3275-5275 \mathrm{GtC}$ scenarios, while it reaches a minimum of about $0.25 \times 10^{6}$ to $0.28 \times 10^{6} \mathrm{~km}^{2}(\sim 5.5$ to $6 \%$ of the year2000 value) in the $2275 \mathrm{GtC}$ scenarios and $2.6 \times 10^{6} \mathrm{~km}^{2}$ 

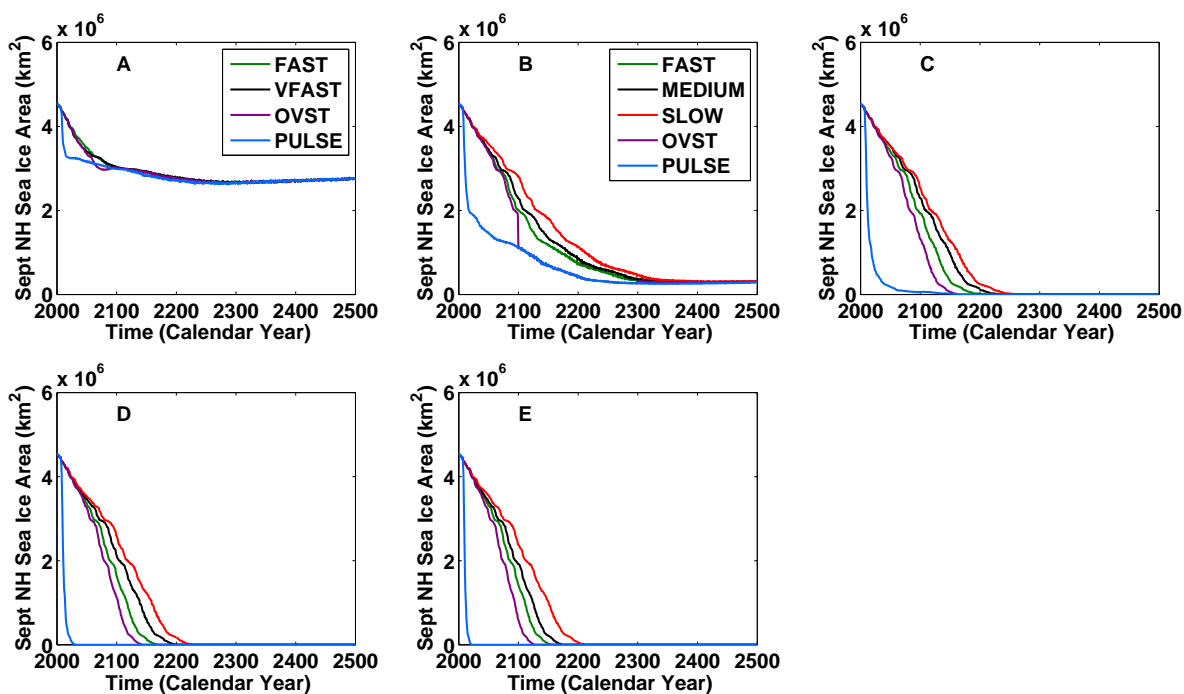

Figure 6. September Northern Hemisphere $(\mathrm{NH})$ sea ice area $\left(\mathrm{km}^{2}\right)$ for the $1275-5275 \mathrm{Gt} \mathrm{C}$ scenarios. (a) $1275 \mathrm{Gt} \mathrm{C}$ scenarios, (b) $2275 \mathrm{Gt} \mathrm{C}$ scenarios, (c) $3275 \mathrm{Gt} \mathrm{C} \mathrm{scenarios,} \mathrm{(d)} 4275 \mathrm{Gt} \mathrm{C}$ scenarios, and (e) $5275 \mathrm{Gt} \mathrm{C}$ scenarios. Note: legend for (b) also applies to (c-e).

in the $1275 \mathrm{Gt} \mathrm{C}$ scenarios $(\sim 58 \%$ of the year- 2000 value; Fig. 6).

The rate of sea ice decline is path dependent and a function of the $\mathrm{CO}_{2}$ emission rate. Emission scenarios with a higher maximum $\mathrm{CO}_{2}$ emission rate display the fastest declines. The minimum sea ice extent, on the other hand, is independent of emission pathway.

Our simulations suggest that there is a threshold cumulative emissions level at which the modeled climate is no longer able to support year-round sea ice cover. Using the definition of an ice-free Arctic adopted by the IPCC's Fourth Assessment Report (AR4), in which a minimum ice extent of $\leq 1.0 \times 10^{6} \mathrm{~km}$ is considered ice free (Solomon et al., 2007), this threshold lies between 1275 and 2275 Gt C.

The UVic model fails to capture the current observed trends of rapid ice loss in the last decade (Comiso, 2012), a problem that plagues many climate models (Stroeve et al., 2007). The inability of the model to simulate the observed decline in sea ice suggests that the threshold cumulative emission levels for an ice-free Arctic in the summer may be lower than indicated by this study.

\subsubsection{Atlantic Meridional Overturning Circulation}

The modeled AMOC index (defined as the maximum of the overturning streamfunction) is $20.7 \mathrm{~Sv}$ in the year 2000 , which is in relatively good agreement with observations ( $\sim$ 12 to $\sim 30 \mathrm{~Sv}$ over the past decade; Send et al., 2011). The simulated AMOC is quite robust, for even in the $5275 \mathrm{GtC}$ scenarios the AMOC index never falls below $13 \mathrm{~Sv}$ or $\sim$ $59 \%$ of the preindustrial value before recovering (Fig. 7). Recovery of the AMOC occurs after temperatures at highlatitudes begin to stabilize and freshwater fluxes into the North Atlantic begin to stabilize or slow, allowing the over- turning circulation to export some of the excess freshwater from the region.

The transient response of the AMOC is dependent on emission pathway - with pathways displaying higher emission rates producing a faster decline and a deeper minimum. The long-term (year-3000) response of the AMOC, however, is path independent, although the curves are slower to converge at higher cumulative emission levels.

Rahmstorf (2000) suggested that the AMOC may be subject to hysteresis or multiple stable states - where the overturning circulation can be on or off, or associated with different locations of deep water formation. The robustness of the AMOC in the UVic model, even at extremely high $\mathrm{CO}_{2}$ concentrations (such as in the case of the $5275 \mathrm{GtC}$ scenarios), either suggests that multiple stability states are not present in the UVic ESCM or that the forcing is below the critical threshold required to induce a state transition. The model, however, does not include all potential feedbacks on the AMOC, including those associated with meltwater fluxes from Greenland, so it is possible that the AMOC decline is underestimated by the model.

\subsection{Relationship between physical climate response and cumulative emissions}

\subsubsection{Surface air temperature}

Consistent with previous studies (Matthews et al., 2009; Zickfeld et al., 2012; Gillett et al., 2013), we find an approximately linear relationship between the modeled instantaneous surface air temperature change $(\Delta T)$ and total cumulative emissions $\left(E_{\mathrm{c}}\right)$ (Fig. 9a). We use linear regression to calculate the ratio of $\Delta T$ to $E_{\mathrm{c}}$, referred to as the TCRE (Gillett et al., 2013). We obtain val- 

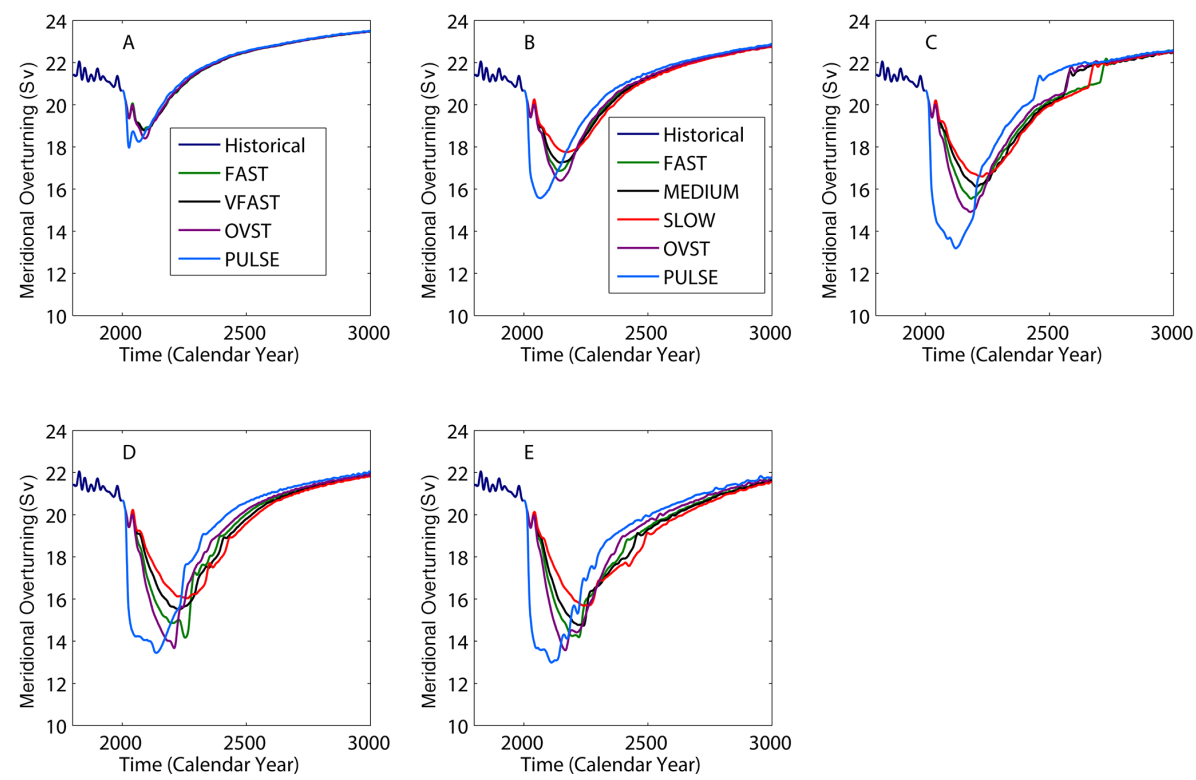

Figure 7. Atlantic Meridional Overturning Circulation (AMOC) index (defined as the meridional overturning streamfunction) for the 1275-5275 GtC scenarios. (a) $1275 \mathrm{GtC}$ scenarios, (b) $2275 \mathrm{GtC}$ scenarios, (c) $3275 \mathrm{GtC}$ scenarios, (d) $4275 \mathrm{GtC}$ scenarios, and (e) $5275 \mathrm{Gt} \mathrm{C}$ scenarios. Note: legend for (b) also applies to (c-e).

ues of 1.9 to $2.0^{\circ} \mathrm{C}$ per trillion tons of carbon $(\mathrm{TtC})$ for the $1275 \mathrm{GtC}$ scenarios, $1.8-1.9{ }^{\circ} \mathrm{CTtC}^{-1}$ for the $2275 \mathrm{GtC}$ scenarios, $1.6-1.7^{\circ} \mathrm{C} \mathrm{Tt}^{-1}$ for the $3275 \mathrm{GtC}$ scenarios, $1.5-1.6^{\circ} \mathrm{C} \mathrm{Tt}^{-1}$ for the $4275 \mathrm{GtC}$ scenarios, and $1.3-1.5^{\circ} \mathrm{C} \mathrm{Tt} \mathrm{C}^{-1}$ for the $5275 \mathrm{GtC}$ scenarios. These results indicate that the TCRE decreases with increasing cumulative emissions. Furthermore, the slight variation of the TCRE within cumulative emission groups suggests that the TCRE is sensitive to the emission rate, with the TCRE decreasing with increasing rates of emission. The TCRE calculated at the time of doubling of the pre-industrial $\mathrm{CO}_{2}$ concentration ranges between $1.7^{\circ} \mathrm{C} \mathrm{TtC}^{-1}$ (for the $5275 \mathrm{GtC}$ OVST scenario) and $1.9^{\circ} \mathrm{C} \mathrm{Tt} \mathrm{C}^{-1}$ (for the $1275 \mathrm{GtC}$ scenarios).

The spread in the regression-based TCRE values of $0.6^{\circ} \mathrm{CTtC}^{-1}$ for the scenarios examined in this study compares to a spread of $1.1^{\circ} \mathrm{C} \mathrm{TtC}^{-1}$ for $\mathrm{C}^{4} \mathrm{MIP}$ models (1.0-2.1 ${ }^{\circ} \mathrm{C} \mathrm{Tt}^{-1}$; Matthews et al., 2009) and $1.6^{\circ} \mathrm{C} \mathrm{Tt}^{-1}$ for CMIP5 models $\left(0.8-2.4^{\circ} \mathrm{C} \mathrm{Tt}^{-1}\right.$; Gillett et al., 2013). This indicates that the sensitivity of the TCRE to emission pathway is substantial, albeit smaller than the sensitivity to structural differences in the suite of $\mathrm{C}^{4} \mathrm{MIP}$ and CMIP5 models.

The tendency for the TCRE to decrease at higher cumulative emissions was noted in earlier studies for cumulative emissions in excess of $2000 \mathrm{GtC}$ (Matthews et al., 2009) and $3000 \mathrm{Gt} C$ (Gillett et al., 2013). The linear relationship between $\Delta T$ and $E_{\mathrm{c}}$ depends on the cancellation of the saturation of carbon sinks with increasing $E_{\mathrm{c}}$ (which results in a larger airborne fraction; see Fig. 9) and the logarithmic dependence of radiative forcing on atmospheric $\mathrm{CO}_{2}$ (which results in a smaller increase in radiative forcing per unit $\mathrm{CO}_{2}$ increase at higher $\mathrm{CO}_{2}$ levels). The decrease in TCRE with increasing $E_{\mathrm{c}}$ suggests that the effect of saturation of the radiative forcing dominates over the effect of a higher airborne fraction of $\mathrm{CO}_{2}$ at higher cumulative emissions in the UVic ESCM.

In a study with the Geophysical Fluid Dynamics Laboratory (GFDL) model using scenarios with a range of linear emission increase rates, Krasting et al. (2014) found the TCRE to increase with increasing emission rates (for emission rates of $5-25 \mathrm{Gt} \mathrm{C} \mathrm{yr}^{-1}$ ), which is the opposite tendency from that found in this study. The TCRE is determined by the effect of the $\mathrm{CO}_{2}$ emission rate on carbon and ocean heat uptake (Krasting et al., 2014): a higher $\mathrm{CO}_{2}$ emission rate results in a larger airborne fraction and hence higher atmospheric $\mathrm{CO}_{2}$ levels and radiative forcing. On the other hand, the climate system is less equilibrated with the radiative forcing, such that a lower fraction of the equilibrium warming is realized compared to scenarios with slower emission rates. Whether the TCRE increases or decrease with higher emission rates depends on the balance between these two processes. Ocean heat and carbon uptake are determined by ocean mixing, and the equilibration timescale is a function of equilibrium climate sensitivity, quantities that differ widely among models. It is therefore conceivable that such differences cause the opposite dependence of TCRE on emission rate in our study compared to that of Krasting et al. (2014).

The version of the UVic ESCM used for this study does not include a permafrost carbon model. Consideration of permafrost carbon would affect the magnitude of warming 

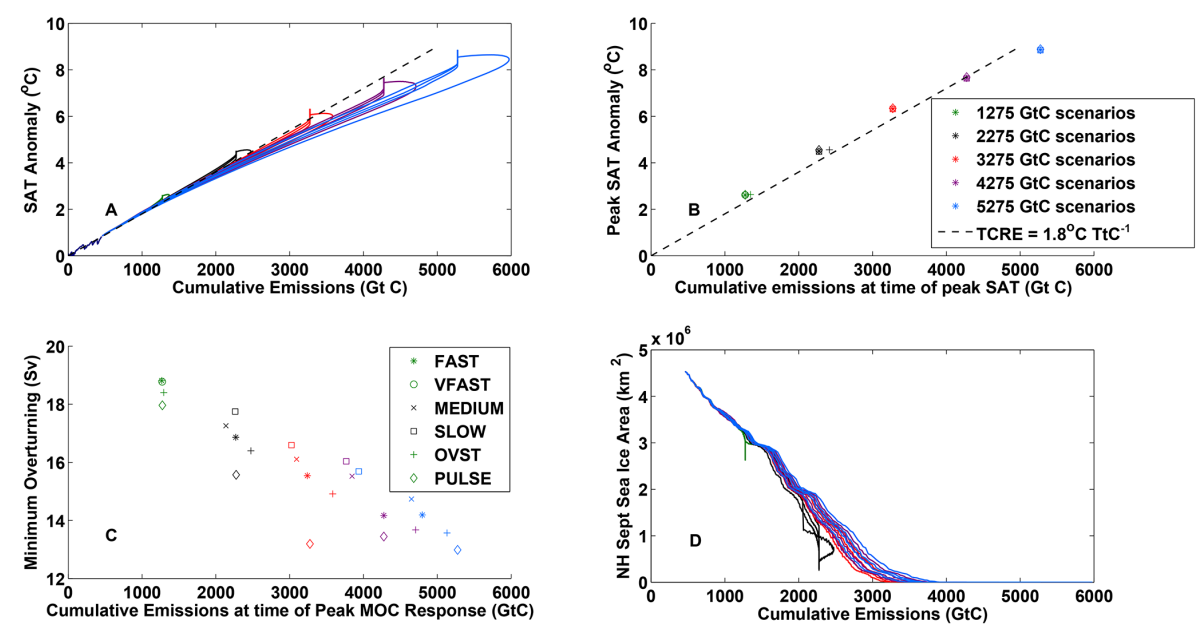

Figure 8. Relationship between physical climate variables and cumulative carbon emissions. (a) Global mean surface air temperature (SAT) anomaly (relative to 1800), (b) peak global mean surface air temperature anomaly (relative to 1800), (c) minimum overturning circulation, and (d) September Northern Hemisphere (NH) sea ice area. The dashed line in (a) and (b) shows the relationship between SAT change and cumulative emissions using the average TCRE computed at the time of $\mathrm{CO}_{2}$ doubling $\left(1.8^{\circ} \mathrm{C} \mathrm{Tt} \mathrm{C}^{-1}\right)$. Note: the color legend in $(\mathbf{b})$ applies to all panels, and the symbol legend in (c) applies to panels (b) and (c).
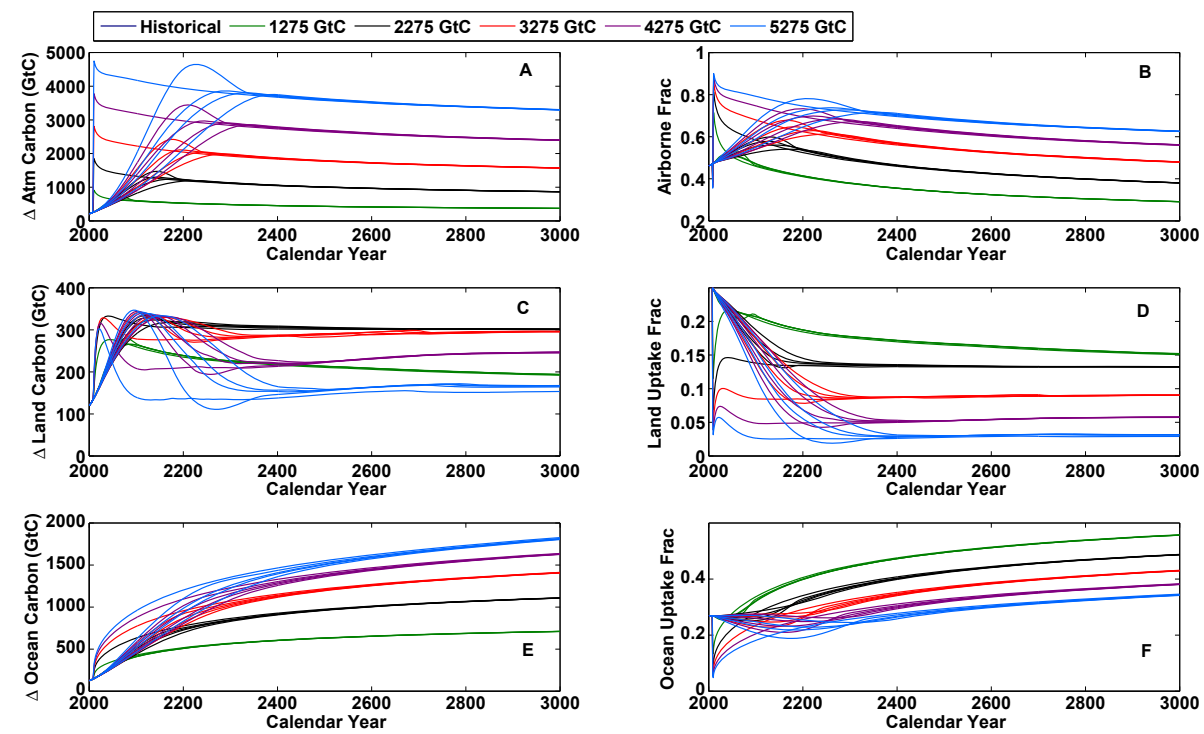

Figure 9. Global carbon cycle response. (a) Atmospheric carbon anomaly (relative to 1800), (b) airborne fraction of cumulative emissions, (c) land carbon anomaly (relative to 1800), (d) fraction of cumulative emissions taken up by the land, (e) ocean carbon anomaly (relative to 1800), and (f) ocean uptake fraction. Note that vertical axes vary.

and could potentially affect the linear relationship between warming and cumulative carbon emissions. As the permafrost thaw depth would increase with warming, it would expose more carbon to decomposition, driving further carbon release - a process known as permafrost carbon feedback (MacDougall et al., 2012). This feedback could affect the airborne fraction and hence the approximate constancy of the TCRE. McDougall (2014) shows that inclusion of the permafrost carbon feedback enhances the sensitivity of the TCRE to the rate of $\mathrm{CO}_{2}$ emissions, with the TCRE declin- ing more strongly with increasing rate of emissions. Overall, however, the permafrost carbon feedback does not appear to compromise the approximately linear relationship between global warming and cumulative carbon emissions (McDougall, 2014). 


\subsubsection{Peak temperature}

The relationship between peak surface air temperature and cumulative emissions (Allen et al., 2009) shows a slight deviation from linearity as cumulative emissions increase (Fig. 8b). Within cumulative emission groups, the peak temperature is approximately independent of the emissions rate, with the exception of the 1275 and 2275 Gt C OVST scenarios. The peak at higher cumulative emissions in the 1275 and $2275 \mathrm{GtC}$ OVST scenarios is the result of the fact that in these scenarios peak temperature occurs during the overshoot phase, whereas in the higher cumulative emission groups peak temperature occurs near the end of the millennium.

\subsubsection{Atlantic Meridional Overturning Circulation}

The peak response of the AMOC is dependent on the emission pathway, with scenarios entailing the highest emission rates yielding the largest declines in overturning circulation. The minimum overturning, unlike peak surface air temperature, does not display a linear relationship with cumulative emissions (Fig. 8c). The minimum overturning shows strong path dependence with higher emission rates yielding a deeper AMOC minimum. We also find that the minimum overturning decreases with increasing cumulative emissions.

The instantaneous AMOC response does not scale well with cumulative emissions either (not shown), consistent with the result from earlier studies (Zickfeld et al., 2012; Nohara et al., 2013).

\subsubsection{Arctic sea ice}

Similar to the findings of Zickfeld et al. (2012), the response of September Arctic sea ice $(\Delta I)$, which is closely correlated with Northern Hemisphere temperature change, scales approximately linearly with cumulative emissions. There generally is, however, a steeper change in sea ice per unit change in cumulative emissions $\left(\Delta I / E_{\mathrm{c}}\right)$ for scenarios with lower rates of emission and lower cumulative emissions (Fig. 8d). This likely arises from the fact that the TCRE declines with increasing cumulative emissions and increasing emission rates.

\subsection{Changes in the carbon cycle}

\subsubsection{Atmospheric carbon burden}

Until emission cessation, the airborne fraction (defined as the ratio of atmospheric carbon burden changes to cumulative emissions) varies substantially across emission pathways within the same cumulative emission group (Fig. 9a and b), and is largest for emission pathways with the highest emission rates. For the $5275 \mathrm{GtC}$ scenarios, the maximum airborne fraction varies between $72 \%$ for the SLOW scenario and $90 \%$ for the PULSE scenario.
The airborne fraction also varies substantially between cumulative emission groups, increasing with increasing cumulative emissions, similar to Plattner et al. (2008) and Zickfeld et al. (2013). For the lower cumulative emission groups $(1275$ and $2275 \mathrm{GtC})$, less than half of the emitted $\mathrm{CO}_{2}$ remains airborne by the year 3000 , while for higher cumulative emission groups more than half of the emitted $\mathrm{CO}_{2}$ still resides in the atmosphere. The year-3000 airborne fraction is $29 \%$ for the $1275 \mathrm{GtC}$ scenarios and $63 \%$ for the $5275 \mathrm{GtC}$ scenarios.

\subsubsection{Ocean carbon uptake}

The ocean takes up a large proportion of the cumulative emissions (Fig. 9e and f). Until emission cessation, ocean carbon uptake is relatively rapid, with $>50 \%$ of the emissions taken up before emissions cease. Uptake slows substantially afterwards, primarily due to declining atmospheric $\mathrm{CO}_{2}$ levels.

The ocean uptake fraction decreases significantly with increasing cumulative emissions. By the year 3000 , ocean carbon uptake amounts to $56 \%$ of cumulative emissions in the $1275 \mathrm{GtC}$ scenarios and $35 \%$ in the $5275 \mathrm{GtC}$ scenarios. The decrease in ocean uptake fraction with increasing cumulative emissions is due to a decrease in the $\mathrm{CO}_{2}$ buffering capacity of the ocean and stronger climate-carbon cycle feedbacks at higher cumulative emissions (Plattner et al., 2008; Zickfeld et al., 2013).

Ocean carbon uptake across the different emission scenarios is slower to converge than for atmospheric $\mathrm{CO}_{2}-\mathrm{a}$ function of the ocean's sluggish response to changes in atmospheric forcing. By the year 3000, however, the differences across scenarios within a cumulative emission group are $<0.5 \%$, even for the $5275 \mathrm{Gt} \mathrm{C}$ scenarios.

\subsubsection{Land carbon uptake}

The terrestrial biosphere takes up a relatively small fraction of the cumulative carbon emissions (3-15\% of the total by the year 3000) but displays interesting dynamics (Fig. 9c and d).

Initially, global land carbon exhibits a rapid increase, driven primarily by the $\mathrm{CO}_{2}$ fertilization effect. Despite much higher peak atmospheric $\mathrm{CO}_{2}$ levels, peak land carbon uptake is very similar in the 2275 to $5275 \mathrm{GtC}$ scenarios, indicating that there is a limit to the amount of carbon which can be taken up by the terrestrial biosphere in the UVic model.

After 2100 or so (earlier in the PULSE scenarios), global land carbon declines in most scenarios. The timing and magnitude of the decline is strongly dependent on the emission scenario (both in terms of total cumulative emissions and emission rate). For the $1275 \mathrm{GtC}$ scenarios, the decline results in losses of about 70 to $130 \mathrm{GtC}$ of land carbon between 2100 and 3000. In the $2275 \mathrm{GtC}$ scenarios, land carbon declines are much more modest, ranging between about 

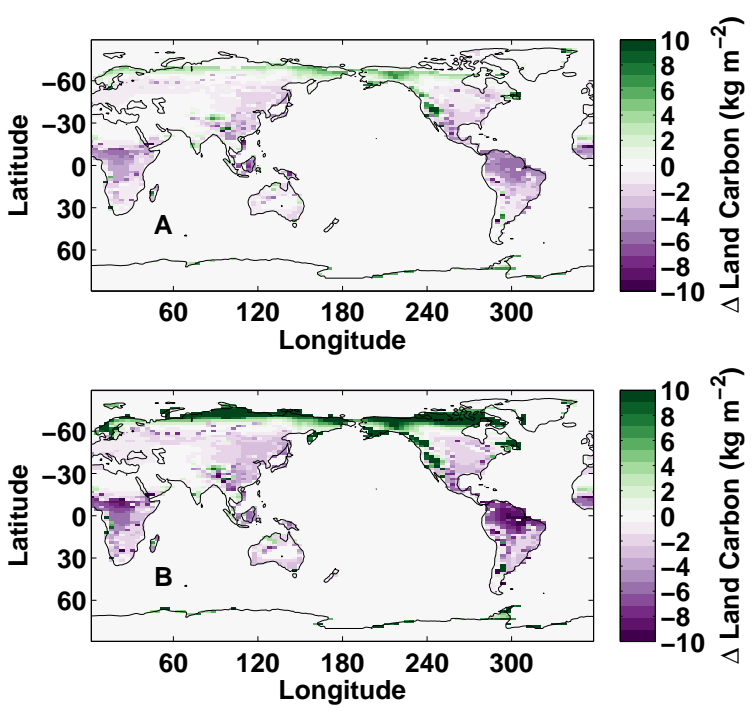

Figure 10. Changes in land carbon for the $5275 \mathrm{GtC}$ FAST scenario. (a) Minimum (year-2310) minus peak (year-2170) total land carbon, and (b) year-2990 minus minumum (year-2310) total land carbon.

20 and $30 \mathrm{GtC}$, as carbon losses in tropical regions are approximately balanced by gains in high-latitude regions.

To some degree in the $3375 \mathrm{GtC}$ scenarios, but noticeably more so in the 4275 and $5275 \mathrm{GtC}$ scenarios, "rollercoaster" type behavior is evident in land carbon, where the initial $\mathrm{CO}_{2}$-fertilization-driven increase of land carbon is followed by a decline, before undergoing a slow recovery towards the end of the simulation. This decline in land carbon after the peak is a result of carbon losses in the tropics (Fig. 10a) associated with temperature-driven mortality of tropical broadleaf forest (in tropical South America, SE Asia, and tropical Africa), and replacement by $\mathrm{C} 4$ grass and shrub. The increase in land carbon following the "dip" is driven by expansion of boreal needleleaf forest, as it displaces shrub and $\mathrm{C} 3$ grass tundra at high latitudes. Land carbon continues to decline in the tropics over this time period but is dominated by land carbon gain at high northern latitudes (Fig. 10b).

Land carbon uptake does not show a monotonic response with increasing cumulative emissions, owing to temperature-related declines at higher cumulative emissions (3275-5275 Gt C) outweighing any $\mathrm{CO}_{2}$-fertilization-driven increase. Despite having the highest atmospheric $\mathrm{CO}_{2}$ concentration, the $5275 \mathrm{GtC}$ scenarios feature the smallest absolute and fractional land carbon uptake, while the $4275 \mathrm{GtC}$ scenarios have the third-highest absolute uptake and the second-smallest fractional uptake. Absolute uptake values increase between the 1275 and $2275 \mathrm{GtC}$ scenarios, before declining, while fractional uptake values are highest in the $1275 \mathrm{GtC}$ scenarios. This suggests that threshold behavior may be occurring in global land carbon, driven by strong temperature related losses at higher levels of cumulative emissions (3275-5275 Gt C).

Slight path dependence is evident in the $5275 \mathrm{Gt} C$ scenarios, with the PULSE scenario showing slightly lower land carbon uptake than the other scenarios (Fig. 9c). Throughout the model integration, the PULSE scenario shows less land carbon uptake at high latitudes and more uptake in the tropics than its counterparts, but by the end of the model integration the land carbon difference in the PULSE scenario originates from central Asia, where $\mathrm{C} 3$ grass is replaced by needleleaf and shrub (not shown), which is not the case in the other scenarios.

The land carbon cycle response to warming and elevated atmospheric $\mathrm{CO}_{2}$ levels differs widely among models (Friedlingstein et al., 2006; Arora et al., 2013; Zickfeld et al., 2013). Compared to other EMICs, land carbon uptake in the UVic ESCM is quite weak (Plattner et al., 2008; Zickfeld et al., 2013). Land carbon uptake in the UVic ESCM exhibits high sensitivities to both $\mathrm{CO}_{2}$ and temperature (Eby et al., 2013), which implies not only a strong $\mathrm{CO}_{2}$ fertilization effect but also strong climate-carbon cycle feedbacks. Unlike previous studies, which found the land uptake fraction to remain relatively constant or decrease slightly with increasing cumulative emissions (Plattner et al., 2008; Zickfeld et al., 2013), we find the land uptake fraction to decrease substantially with increasing cumulative emissions. These previous studies, however, explored a narrower range of cumulative emissions (up to about $3800 \mathrm{Gt} \mathrm{C}$ in Zickfeld et al., 2013).

The exclusion of permafrost carbon from this study could potentially affect land carbon uptake in a future climate. MacDougall et al. (2012) utilized a modified version of the UVic ESCM with a coupled permafrost carbon model and found that permafrost soils could release between 68 and $508 \mathrm{Gt} C$ by 2100 under the RCP $2.6-8.5$ scenarios - on the same order of magnitude as the global land carbon uptake values found in this study. The addition of permafrost carbon could turn large portions of the high-latitude regions into net sources of carbon (MacDougall et al., 2012), and the added warming, in addition to fueling further carbon release from permafrost regions through feedback loops, could exacerbate the declines in land carbon exhibited by tropical regions in this study.

Another source of uncertainty in land carbon uptake is the coupling between the carbon and the nitrogen cycle. The land carbon cycle component of the UVic ESCM, like most land carbon cycle models, does not include a representation of the nitrogen cycle. In models that include coupled carbon and nitrogen cycles, the $\mathrm{CO}_{2}$ fertilization effect under future $\mathrm{CO}_{2}$ levels is reduced, since enhanced plant growth increases its need for mineralized nitrogen, and associated increases in litter inputs to the soil carbon pool can increase microbial demand for nitrogen (meaning there would be less available for plant use) (Thornton et al., 2007). This may suggest that the UVic ESCM could be overestimating the effects of $\mathrm{CO}_{2}$ fertilization on land carbon uptake. Though plant and microbial 
nitrogen demand may increase in a warmer climate, the availability of usable nitrogen may also increase in a warmer climate (Rustad et al., 2001), which would reduce the negative effect that nitrogen limitation exerts on $\mathrm{CO}_{2}$ fertilization.

\section{Summary and conclusions}

This study explores the path dependence of the climate and carbon cycle response under $\mathrm{CO}_{2}$ scenarios spanning a broad range of cumulative emissions and emission rates. We use the UVic Earth System Model of intermediate complexity, which is forced with $24 \mathrm{CO}_{2}$ emission scenarios across five cumulative emission groups $(1275,2275,3275,4275$, and $5275 \mathrm{GtC}$ ). Each cumulative emission group includes a variety of peak and decline scenarios with differing emission rates, an overshoot scenario, and an instantaneous pulse scenario.

Our results indicate that the century-scale global mean temperature response after cessation of $\mathrm{CO}_{2}$ emissions is independent of emission pathway and proportional to cumulative emissions, consistent with the findings of previous studies (Eby et al., 2009; Zickfeld et al., 2009, 2012; Nohara et al., 2013).

The ratio of global mean temperature change to cumulative emissions - referred to as the TCRE - is found to be constant for cumulative emissions lower than $\sim 1500 \mathrm{GtC}$, but to decline with higher cumulative emissions. The TCRE is also found to decrease with increasing peak emission rate, in contrast to the results from another study (Krasting et al., 2014).

The century-scale thermosteric sea level rise is also found to be approximately independent of emission pathway. Small differences in sea level rise between scenarios within the same cumulative emisson group at the end of the simulation arise from the sluggish response of the ocean to radiative forcing.

Similarly to global mean temperature and thermosteric sea level rise, we find the long-term response of Arctic September sea ice cover to be independent of emission pathway and determined only by cumulative emissions. The longterm sea ice cover declines with increasing cumulative emissions, with a critical cumulative emission level for the loss of year-round Arctic sea ice found to be between 1275 and 2275 Gt C. Changes in Arctic September sea ice cover also show an approximately proportional relationship with cumulative emissions, with the change in sea ice cover per unit change in cumulative emissions differing slightly across scenarios and cumulative emission groups.

The peak response of the AMOC is found to be path dependent, with pathways featuring higher emission rates yielding the largest AMOC decline. Eventually, however, the AMOC responses converge, and there is little difference in the year-3000 AMOC strength across scenarios within a cumulative emission group. At no point does the AMOC shut down in any of the 24 scenarios, suggesting that either the AMOC in the UVic ESCM does not exhibit multiple stable states or that the critical transition point was not reached.

Similarly to the physical climate variables, the centuryscale carbon cycle response after cessation of emissions is found to be approximately independent of emission pathway. Small differences in year-3000 ocean carbon uptake between scenarios at high cumulative emission levels arise from the slow response of the ocean to changes in atmospheric $\mathrm{CO}_{2}$ and temperature. We also find a small difference in year3000 land carbon uptake between scenarios at high cumulative emissions $(5275 \mathrm{Gt} \mathrm{C})$ due to hysteresis in regional landcover changes.

The year-3000 land carbon uptake exhibits a nonmonotonic response to cumulative $\mathrm{CO}_{2}$ emissions, with land carbon uptake increasing for cumulative emissions up to $2275 \mathrm{Gt} \mathrm{C}$ and then decreasing. This indicates that, for cumulative emissions greater than $2275 \mathrm{GtC}$, land carbon gains associated with the $\mathrm{CO}_{2}$ fertilization effect are more than offset by warming-related losses. Expressed as a fraction of cumulative emissions, land carbon uptake at year 3000 is largest for the $1275 \mathrm{GtC}$ scenarios (15\%) and declines with increasing cumulative emissions, to just $3 \%$ for the $5275 \mathrm{GtC}$ scenarios.

Ocean carbon uptake at year 3000 increases in absolute terms with increasing cumulative emissions, as a function of increasing atmospheric $\mathrm{CO}_{2}$ levels at higher cumulative emissions. The fraction of cumulative $\mathrm{CO}_{2}$ emissions taken up by the ocean at the year 3000 decreases with increasing cumulative emissions, from $56 \%$ in the $1275 \mathrm{Gt} C$ scenarios to $35 \%$ in the $5275 \mathrm{GtC}$ scenarios. As a result of reduced fractional land and carbon uptake with increasing cumulative emissions, the year-3000 airborne fraction of $\mathrm{CO}_{2}$ increases with increasing cumulative emissions, from $29 \%$ in the $1275 \mathrm{GtC}$ scenarios to $63 \%$ in the $5275 \mathrm{GtC}$ scenarios.

In summary, this study shows that the long-term climate and carbon cycle response is approximately independent of emission pathway over a broad range of cumulative emissions. This study also confirms the approximately proportional relationship between global warming and cumulative carbon emissions. The TCRE deviates from constancy for cumulative emissions greater than $\sim 1500 \mathrm{GtC}$ and is sensitive to the rate of emissions, but these path dependencies are a smaller source of uncertainty in the TCRE than inter-model differences.

Author contributions. K. Zickfeld conceived the study, T. Herrington and $\mathrm{K}$. Zickfeld designed the model experiments, T. Herrington performed the model simulations and analyzed the data, and T. Herrington and K. Zickfeld interpreted the data and wrote the manuscript. 
Acknowledgements. K. Zickfeld acknowledges support from the National Science and Engineering Research Council (NSERC) CREATE and Discovery Grant programs.

Edited by: M. Huber

\section{References}

Allen, M., Frame, D., Huntingford, C., Jones, C. D., Lowe, J. A., Meinshausen, M., and Meinshausen, N.: Greenhouse-gas emission targets for limiting global warming to $2^{\circ} \mathrm{C}$, Nature, 458 , 1163-1166, 2009.

Archer, D.: A data-driven model of the global calcite lysocline, Global Biogeochem. Cy., 10, 511-526, 1996.

Arora, V. K., Boer, G. J., Friedlingstein, P., Eby, M., Jones, C. D., Christian, J. R., Bonan, G., Bopp, L., Brovkin, V., Cadule, P., Hajima, T., Ilyina, T., Lindsay, K., Tjiputra, J. F., and Wu, T.: Carbon-Concentration and Carbon-Climate Feedbacks in CMIP5 Earth System Models, J. Climate, 26, 5289-5314, 2013.

Boden, T. A., Marland, G., and Andres, R. J.: Carbon Dioxide Information Analysis Center, Oak Ridge National Laboratory, U.S. Department of Energy, Oak Ridge, Tenn., USA available at: http://cdiac.ornl.gov/trends/emis/tre_glob_2009.html, last access: 30 September 2012.

Bouttes, N., Gregory, J. M., and Lowe, J. A.: The Reversibility of Sea Level Rise, J. Climate, 26, 2502-2513, 2013.

Comiso, J. C.: Large decadal decline of the Arctic multiyear ice cover. J. Climate, 25, 1176-1193, 2012.

Eby, M., Zickfeld, K., Montenegro, A., Archer, D., Meissner, K., and Weaver, A.: Lifetime of anthropogenic climate change: millennial time scales of potential $\mathrm{CO}_{2}$ and surface temperature perturbations, J. Climate, 22, 2501-2511, 2009.

England, M. H., Gupta, A. S., and Pitman, A. J.: Constraining future greenhouse gas emissions by a cumulative target, P. Natl. Acad. Sci. USA, 106, 16539-16540, 2009.

Friedlingstein, P., Cox, P., Betts, R., Bopp, L., Von Bloh, W., Brovkin, V., Cadule, P., Doney, S., Eby, M., and Fung, I.: Climate-carbon cycle feedback analysis: Results from the C4MIP model intercomparison, J. Climate, 19, 3337-3353, 2006.

Frölicher, T. L. and Joos, F.: Reversible and irreversible impacts of greenhouse gas emissions in multi-century projections with the NCAR global coupled carbon cycle-climate model, Clim. Dynam., 35, 1439-1459, 2010.

Frölicher, T. L., Winton, M., and Sarmiento, J. L.: Continued global warming after $\mathrm{CO}_{2}$ emissions stoppage, Nature Clim. Change, 4 , 40-44, 2014.

Gent, P. R. and McWilliams, J. C.: Isopycnal mixing in ocean circulation models, J. Phys. Oceanogr., 20, 150-155, 1990.

Gillett, N. P., Arora, V. K., Zickfeld, K., Marshall, S. J., and Merryfield, W. J.: Ongoing climate change following a complete cessation of carbon dioxide emissions. Nat. Geosci., 4, 83-87, 2011.

Gillett, N. P., Arora, V. K., Matthews, H. D., and Allen, M. R.: Constraining the ratio of global warming to cumulative $\mathrm{CO}_{2}$ emissions using CMIP5 simulations, J. Climate., 26, 6844-6858, 2013.

Houghton, R. A.: Carbon Dioxide Information Analysis Center, Oak Ridge National Laboratory, U.S. Department of Energy,
Oak Ridge, Tenn., USA, http://cdiac.ornl.gov/trends/landuse/ houghton/houghton.html (last access: 30 September 2012), 2008.

Krasting, J. P., Dunne, J. P., Shevliakova, E., and Stoufer, R. J.: Trajectory sensitivity of the transient climate response to cumulative carbon emissions, Geophys. Res. Lett., 41, 2520-2527, 2014.

Lowe, J. A., Huntingford, C., Raper, S. C. B., Jones, C. D., Liddicoat, S. K., and Gohar, L. K.: How difficult is it to recover from dangerous levels of global warming?, Environ. Res. Lett., 4, 014012, doi:10.1088/1748-9326/4/1/014012, 2009.

MacDougall, A. H.: A modelling study of the permafrost carbon cycle feedback to climate change: feedback strength, timing, and carbon cycle consequences, $\mathrm{PhD}$ thesis, University of Victoria, BC, Canada, 118 pp., 2014.

MacDougall, A. H., Avis, C. A., and Weaver, A. J.: Significant contribution to climate warming from the permafrost carbon feedback, Nat. Geosci., 5, 719-721, 2012.

Matthews, H. D. and Caldeira, K.: Stabilizing climate requires nearzero emissions, Geophys. Res. Lett., 35, L04705, 2008.

Matthews, H. D., Gillett, N. P., Stott, P. A., and Zickfeld, K.: The proportionality of global warming to cumulative carbon emissions, Nature, 459, 829-832, 2009.

Meinshausen M., Meinshausen, N., Hare, W., Raper S., Frieler, K., Knutti, R., Frame, D., and Allen, M.: Greenhouse-gas emission targets for limiting global warming to $2^{\circ} \mathrm{C}$, Nature, 458 , 1158-1162, 2009.

Meissner, K., Weaver, A., Matthews, H., and Cox, P.: The role of land surface dynamics in glacial inception: A study with the UVic, Earth System Model. Clim. Dyn., 21, 515-537, 2003.

Messner, D., Schellnhuber, J., Rahmstorf, S., and Klingenfeld, D.: The budget approach: A framework for a global transformation toward a low-carbon economy, J. Renew. Sustain. Energy, 2, 1-14, 2010.

Nohara, D., Yoshida, Y., Misumi, K., and Ohba, M.: Dependency of climate change and carbon cycle on $\mathrm{CO}_{2}$ emission pathways, Environ. Res. Lett., 8, 014047, doi:10.1088/1748-9326/8/1/014047, 2013.

Plattner, G., Knutti, R., Joos, F., Stocker, T., Von Bloh, W., Brovkin, V., Cameron, D., Driesschaert, E., Dutkiewicz, S., and Eby, M.: Long-term climate commitments projected with climate-carbon cycle models, J. Climate, 21, 2721-2751, 2008.

Rahmstorf, S.: The thermohaline ocean circulation: A system with dangerous thresholds?, Clim. Change, 46, 247-256, 2000.

Rustad, L., Campbell, J., Marion, G., Norby, R., Mitchell, M., Hartley, A., Cornelissen, J., and Gurevitch, J.: A meta-analysis of the response of soil respiration, net nitrogen mineralization, and aboveground plant growth to experimental ecosystem warming, Oecologia, 126, 543-562, 2001.

Schmittner, A., Oschlies, A., Giraud, X., Eby, M., and Simmons, H.: A global model of the marine ecosystem for long-term simulations: Sensitivity to ocean mixing, buoyancy forcing, particle sinking, and dissolved organic matter cycling, Global Biogeochem. Cy., 19, GB3004, doi:10.1029/2004GB002283, 2005.

Send, U., Lankhorst, M., and Kanzow, T.: Observation of decadal change in the Atlantic meridional overturning circulation using 10 years of continuous transport data, Geophys. Res. Lett., 38, L24606, doi:10.1029/2011GL049801, 2011.

Solomon, S., Qin, D., and Manning, M.: Climate Change 2007: The Physical Science Basis, Working Group I Contribution to the Fourth Assessment Report of the Intergovernmental Panel on 
Climate Change, Cambridge University Press, Cambridge, UK, 2007.

Solomon, S., Plattner, G., Knutti, R., and Friedlingstein, P.: Irreversible climate change due to carbon dioxide emissions, P. Natl. Acad. Sci. USA, 106, 1704-1709, 2009.

Stroeve, J., Holland, M. M., Meier, W., Scambos, T., and Serreze, M.: Arctic sea ice decline: Faster than forecast, Geophys. Res. Lett., 34, L09501, doi:10.1029/2007GL029703, 2007.

Thornton, P. E., Lamarque, J., Rosenbloom, N. A., and Mahowald, N. M.: Influence of carbon-nitrogen cycle coupling on land model response to $\mathrm{CO}_{2}$ fertilization and climate variability, Global Biogeochem. Cy., 21, GB4018, doi:10.1029/2006GB002868, 2007.

Weaver, A. J., Eby, M., Wiebe, E. C., Bitz, C. M., Duffy, P. B., Ewen, T. L., Fanning, A. F., Holland, M. M., MacFadyen, A., and Matthews, H. D.: The UVic Earth System Climate Model: Model description, climatology, and applications to past, present and future climates, Atmosphere-Ocean, 39, 361-428, 2001.
Wullschleger, S., Tschaplinski, T., and Norby, R.: Plant water relations at elevated $\mathrm{CO}_{2}$-implications for water-limited environments, Plant. Cell Environ., 25, 319-331, 2002.

Zickfeld, K., Eby, M., Matthews, H. D., and Weaver, A. J.: Setting cumulative emissions targets to reduce the risk of dangerous climate change, P. Natl. Acad. Sci. USA, 106, 16129-16134, 2009.

Zickfeld, K., Arora, V. K., and Gillett, N. P.: Is the climate response to $\mathrm{CO}_{2}$ emissions path dependent?, Geophys. Res. Lett., 39, L05703, doi:10.1029/2011GL050205, 2012.

Zickfeld, K., Eby, M., Weaver, A., Alexander, K., Crespin, E., Edwards, N., Eliseev, A., Feulner, G., Fichefet, T., Forest, C., Friedlingstein, P., Goosse, H., Holden, P., Joos, F., Kawamiya, M., Kicklighter, D., Kienert, H., Matsumoto, K., Mokhov, I., Monier, E., Olsen, S., Pedersen, O., Perrette, M., Berthier, G., Ridgwell, A., Schlosser, A., Schneider Von Deimling, T., Shaffer, G., Sokolov, A., Spahni, R., Steinacher, M., Tachiiri, K., Tokos, K., Yoshimori, M., Zeng, N., and Zhao, F.: Long-term climate change commitment and reversibility: An EMIC intercomparison, J. Climate, 26, 5782-5809, 2013. 